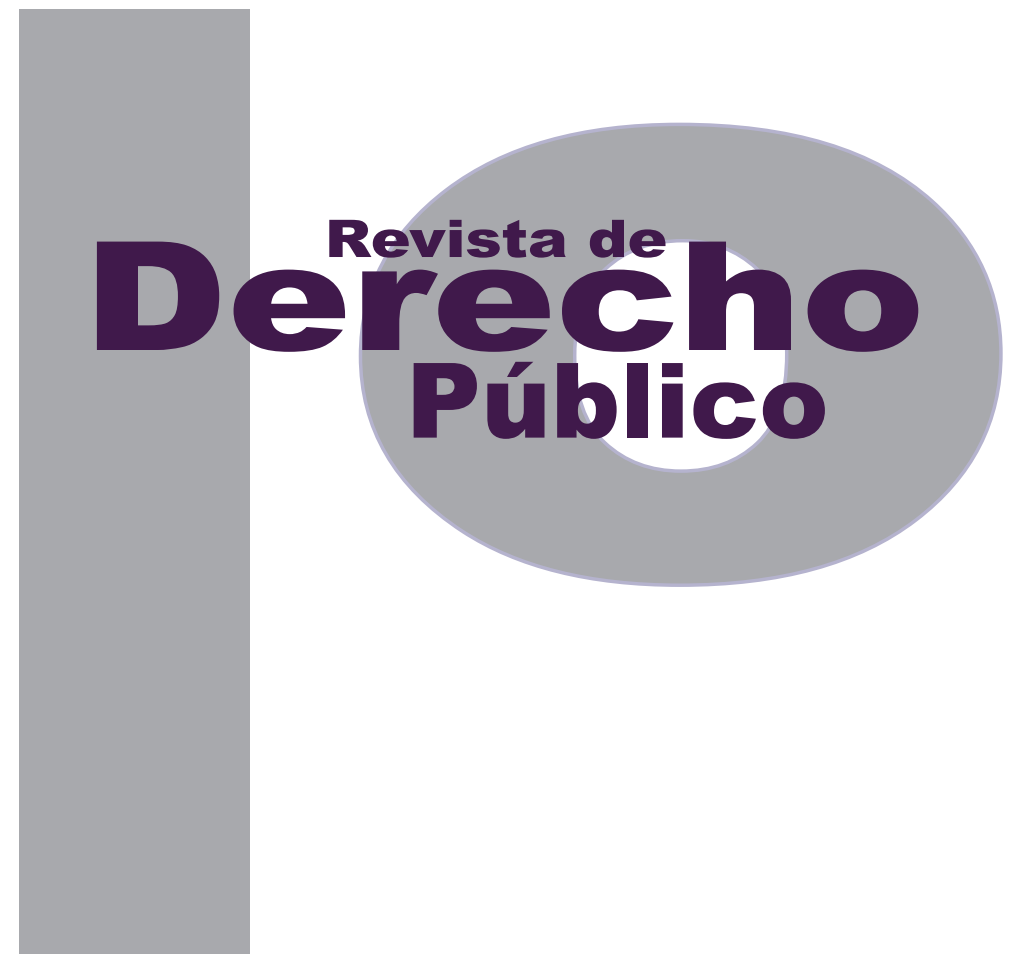

\title{
APUNTES SOBRE LA CONSTITUCIONALIZACIÓN DE LA JUSTICIA TRANSICIONAL EN COLOMBIA. ESTUDIO DE LA SENTENCIA C-579 DE 2013 DE LA CORTE CONSTITUCIONAL DE COLOMBIA
}

\author{
DANIEl MARÍn López \\ Documento de reflexión no derivado de investigación \\ DOI: http://dx.doi.org/10.15425/redepub.34.2015.06 \\ Universidad de los Andes \\ Facultad de Derecho \\ Revista de Derecho Público N. ${ }^{\circ} 34$ \\ Enero - Junio de 2015. ISSN 1909-7778
}




\section{Apuntes sobre la constitucionalización de la justicia transicional en Colombia. Estudio de la sentencia c-579 de 2013 de la corte constitucional de Colombia}

\section{Resumen}

La promulgación del Marco Jurídico para la Paz que adicionó los artículos 66 y 67 transitorios a la Constitución Política, ha abierto toda clase de discusiones acerca de la viabilidad de los mecanismos de justicia transicional en Colombia. Este artículo tiene como objetivo analizar la sentencia C-579 de 2013 de la Corte Constitucional, que declaró exequible dicho Marco. Se centra en los argumentos que esta ofrece en torno a los mecanismos de selección y priorización de casos con base en el llamado juicio estricto de sustitución. En particular, busca resaltar la regla de derecho que se desprende de esta decisión y los debates que han surgido alrededor de los argumentos que soporta la regla y que constituyen los pilares de la justicia transicional en Colombia. La conclusión a la que se llega es que la Corte en la sentencia bajo estudio no realizó un juicio de sustitución riguroso, situación que provoca que la regla constitucional referente a la justicia transicional no esté clara. Por tanto, la ratio definida en la presente sentencia puede no ser seguida en posteriores fallos de constitucionalidad que versen sobre el mismo Marco.

Palabras clave: Marco Jurídico para la Paz, Corte Constitucional, selección, priorización, máximos responsables, juicio de sustitución, delitos internacionales.

\section{Notes about the Constitutionalization of Transitional Justice in Colombia. Study of the Sentence C-579 of 2013 of the Constitutional Court of Colombia}

\section{Abstract \\ The promulgation of the so-called Legal Framework for Peace that added the transitory Articles 66 and 67 to the Colom- bian Constitution has been open to all kinds of discussions about the viability of the mechanisms of transitional justice in Colombia. This article's aim is to analyze the sentence C-579 of 2013 of the Constitutional Court of Colombia which declared this Framework constitutional. It focuses on the arguments that the sentence offers regarding the mechanisms of selection and prioritization of cases based on a strict judgment of substitution. In particular, it seeks to enhance the ratio decidendi that emerges from this decision and the debates that have arisen around the arguments that support that ratio and constitute the pillars of Transitional Justice in Colombia. The conclusion is that the Court in its decision did not make a judgment of strict substitution, situation that leaves the constitutional rule about Transitional Justice unclear. Therefore, the ratio defined in this sentence could not be followed in subsequent constitutional decisions that deal with the same Framework. \\ Keywords: Legal Framework for Peace, Constitutional Court, selection, prioritization, heads, judgement of substitution, international crimes. \\ Anotações sobre a constitucionalização da justiça transicional na Colômbia. Estudo da sentença c-579 de 2013 da corte constitucional da Colômbia}

\section{Resumo}

A promulgação do Marco Jurídico para a Paz que adicionou os artigos 66 e 67 transitórios à Constituição Política, tem aberto todo tipo de discussões acerca da viabilidade dos mecanismos de justiça transicional na Colômbia. Este artigo tem como objetivo analisar a sentença C-579 de 2013 da Corte Constitucional, que declarou exequível dito Marco. 0 artigo se centra nos argumentos que esta oferece em torno aos mecanismos de seleção e priorização de casos com base no chamado juízo estrito de substituição. Em particular, busca ressaltar a regra de direito que se desprende desta decisão e os debates que têm surgido ao redor dos argumentos que dá suporte à regra e que constituem os pilares da justiça transicional na Colômbia. A conclusão é que a Corte na sentença sob estudo não realizou um juízo de substituição rigoroso, situação que provoca que a regra constitucional referente à justiça transicional não esteja clara. Portanto, a ratio definida na presente sentença pode não ser seguida em posteriores falhos de constitucionalidade que versem sobre o mesmo Marco.

Palavras-chave: Marco Jurídico para a Paz, Corte Constitucional, seleção, priorização, máximos responsáveis, juízo de substituição, delitos internacionais. 


\title{
Apuntes sobre la constitucionalización de la justicia transicional en Colombia. Estudio de la sentencia c-579 de 2013 de la corte constitucional de Colombia*
}

\author{
Daniel Marín López ${ }^{* *}$
}

\section{SUMARIO}

Introducción - I. ANÁLISIS DE LOS CARGOS FORMULADOS EN CONTRA DE LAS DISPOSICIONES DEL M.J.P. - II. RATIO DECIDENDI - III. ARGUMENTOS QUE TUVO LA CORTE PARA SOPORTAR DICHA REGLA - A. Posibilidad de centrar los esfuerzos en la investigación penal en la persecución de los delitos internacionales como los delitos de lesa humanidad, los crímenes de guerra y el genocidio - B. Sobre la expresión "cometidos de manera sistemática" - C. Respecto a la expresión "máximos responsables" - D. Sobre la renuncia condicionada a la persecución penal - E. Criterios del muP que deben estar contemplados en las leyes estatutarias - IV. CRITICA AL JUICIO DE SUSTITUCIÓN ELABORADO POR LA CORTE - Referencias.

Cómo citar este artículo: Marín López, D. (Junio, 2015). Apuntes sobre la constitucionalización de la justicia transicional en Colombia. Estudio de la sentencia C-579 de 2013 de la Corte Constitucional de Colombia. Revista de Derecho Público, 34. Universidad de los Andes (Colombia).

** Abogado y politólogo de la Universidad de los Andes. Actualmente se desempeña como investigador en temas relacionados con conflicto armado y justicia transicional. Correo: d.marinlopez1@gmail.com 


\section{Introducción}

Tras más de diez años de implementación de la Ley de Justicia y Paz y con la instalación de la mesa de conversaciones entre la cincuentenaria guerrilla de las Fuerzas Armadas Revolucionarias de Colombia (FARC) y el gobierno coIombiano, los debates sobre la forma en que se afrontará el postconflicto en un país actualmente en conflicto están a la orden del día. Quizá el tema más álgido es el que tiene que ver con la manera en la que los perpetradores de graves violaciones a los derechos humanos (DD. HH.) e infracciones al derecho internacional humanitario (DIH) deberán ser investigados y juzgados en el corto a mediano plazo. Con la promulgación del Ilamado Marco Jurídico para la Paz (msp) por parte del Congreso de la República, mediante el Acto Legislativo 01 del 31 de julio de 2012 que adicionó a la Constitución Política los artículos 66 y 67 transitorios, se ha abierto toda clase de discusiones acerca de la viabilidad de los mecanismos de justicia transicional (JT) que trajo dicho instrumento jurídico. Entre estos se destacan: la autorización para un tratamiento diferenciado de los distintos grupos armados organizados al margen de la ley (GAOML), la posibilidad de establecer mecanismos judiciales y extrajudiciales de sт, la creación de una Comisión de la Verdad, la estrategia de priorización y selección que concentre la investigación penal en los máximos responsables y, finalmente, la posibilidad de participación en política de los desmovilizados condenados por delitos políticos y conexos.
El presente documento de análisis se centrará en los debates en torno a los criterios de priorización y selección dentro de la investigación penal. Particularmente, en lo determinado por la Corte Constitucional en la sentencia C-579 de 2013, donde con ponencia del magistrado Jorge Ignacio Pretelt Chaljub declaró la exequibilidad del inciso $4^{\circ}$ del artículo $1^{\circ}$ del Acto Legislativo. ${ }^{1}$ En términos generales, la sentencia examinó si los criterios de priorización y selección en la investigación penal como instrumento inherente a la st constituían una sustitución de la Carta Política, en tanto esta tiene un pilar fundamental basado en el "deber del Estado de garantizar los derechos humanos, y por consiguiente, investigar y juzgar adecuadamente todas las graves violaciones de derechos humanos y las infracciones al derecho internacional humanitario cometidas en su jurisdicción" (Gallón, Esparza, Díaz y Rivera, 2012, p. 2).

En esta labor, la Corte Constitucional estaba frente a una situación sin precedentes pues era la primera vez que debía ponderar median-

1 El inciso $4^{\circ}$ del artículo $1^{\circ}$ del Acto Legislativo consagra: "Tanto los criterios de priorización como los de selección son inherentes a los instrumentos de justicia transicional. El Fiscal General de la Nación determinará criterios de priorización para el ejercicio de la acción penal. Sin perjuicio del deber general del Estado de investigar y sancionar las graves violaciones a los Derechos Humanos y al Derecho Internacional Humanitario, en el marco de la justicia transicional, el Congreso de la República, por iniciativa del Gobierno Nacional, podrá mediante ley estatutaria determinar criterios de selección que permitan centrar los esfuerzos en la investigación penal de los máximos responsables de todos los delitos que adquieran la connotación de crímenes de lesa humanidad, genocidio, o crímenes de guerra cometidos de manera sistemática; establecer los casos, requisitos y condiciones en los que procedería la suspensión de la ejecución de la pena; establecer los casos en los que proceda la aplicación de sanciones extrajudiciales, de penas alternativas, o de modalidades especiales de ejecución y cumplimiento de la pena; y autorizar la renuncia condicionada a la persecución judicial penal de todos los casos no seleccionados. La ley estatutaria tendrá en cuenta la gravedad y representatividad de los casos para determinar los criterios de selección." [Cursivas añadidas]. 
te juicio de sustitución el derecho a la paz y los instrumentos de JT con el derecho a la justicia. ${ }^{2}$ En ocasiones anteriores, la Corte había tenido la oportunidad de estudiar los alcances que podía tener la justicia de transición, especialmente en las sentencias C-370 de 2006, C-771 de 2011, C-715 de 2012 y C-099 de 2013, sin embargo en aquellas ocasiones las decisiones de esta corporación se centraban en estudiar la exequibilidad de un precepto legal que consagraba instrumentos jurídicos de गт de acuerdo con la Constitución. En esta decisión que se estudiará, la Corte tuvo que realizar un ejercicio de ponderación de principios constitucionales, en tanto dichos instrumentos de JT fueron elevados al rango de normatividad superior desde el mismo momento que el msp fue promulgado. Ahora, para determinar la exequibilidad de dichos instrumentos, la Corte Constitucional debía seguir la senda de un juicio de sustitución que comprende, al menos en la teoría, un estudio riguroso de los principios constitucionales en colisión. ${ }^{3}$

2 En efecto, el problema jurídico que se planteó la Corte Constitucional en el presente proceso quedó consignado en el fundamento $3^{\circ}$ en los siguiente términos: "En este sentido el problema jurídico planteado es si sustituye la Constitución la posibilidad de que se utilicen los criterios de selección y priorización para la investigación, el juzgamiento y la sanción de los más graves crimenes contra loS $\mathrm{DH}$ y el DIH cometidos por los máximos responsables y se renuncie a la persecución de los demás. En todo caso, como se verá más adelante, para poder estudiar este problema jurídico es necesario estudiar además: (i) la posibilidad de centrar los esfuerzos en la investigación penal (ii) en los máximos responsables de (iii) todos los delitos que adquieran la connotación de crímenes de lesa humanidad, genocidio, o crímenes de guerra, (iv) cometidos de manera sistemática, (v) autorizar la renuncia condicionada a la persecución judicial penal de todos los casos no seleccionados, y (vi) la aplicación de penas alternativas, sanciones extrajudiciales, la suspensión condicional de la ejecución de la pena o mecanismos especiales para el cumplimiento de la pena." [Cursivas añadidas].

3 Para un estudio del juicio de sustitución ver el acápite IV del presente documento.
Por lo anterior, el objetivo central del presente escrito es analizar la sentencia centrándose en los argumentos que esta ofrece con respecto a los mecanismos de selección y priorización de casos que consagra el Acto Legislativo. En particular, busca resaltar la regla de derecho que se desprende de esta decisión y los debates que han surgido en torno a los argumentos que soporta la regla y que constituyen los pilares de la JT en Colombia.

La metodología utilizada parte de un estudio en profundidad del contenido de la demanda de inconstitucionalidad interpuesta por la Comisión Colombiana de Juristas y de la sentencia C-579 de 2013, con el ánimo de poner en diálogo ambas posiciones acerca de los mecanismos de JT contemplados en el Acto Legislativo. Posteriormente, se realizó un examen de la bibliografía que tratara temas relacionados con el Acto Legislativo en mención, con el fin de enriquecer el debate inicial. Finalmente, se estudió la jurisprudencia constitucional relevante sobre el juicio de sustitución, con el objeto de comparar la forma en que la Corte lo había realizado en ocasiones previas con motivo de los análisis de constitucionalidad de los actos legislativos versus la manera como lo abordó en la presente decisión.

Con esto en mente, este escrito se dividirá en tres partes. En primer lugar, se hará un análisis de los cargos formulados en contra de las disposiciones del MJP anteriormente mencionados. En segundo lugar, se presentará la regla de derecho o ratio decidendi que creó la Corte en el presente juicio de constitucionalidad. ${ }^{4}$ En tercer

4 La figura de la ratio decidendi busca desentrañar la regla de derecho que surge de las consideraciones adoptadas por un órgano judicial en 
lugar, se expondrán los argumentos que tuvo la Corte para soportar dicha regla, realizando las respectivas anotaciones a sus razonamientos.

Se tendrá como tesis central que la Corte en la sentencia bajo estudio no realizó un juicio de sustitución riguroso, situación que provoca que la regla constitucional en torno a la Jт no esté clara y que, por tanto, la ratio definida en la sentencia en estudio no pueda ser seguida en posteriores fallos de constitucionalidad que versen sobre el mismo Acto Legislativo. Por tanto, en el desarrollo de la sentencia este se tornó autojustificativo, es decir, en vez de consolidar un estudio de ponderación de los principios constitucionales en colisión, se elaboró una justificación del porqué los instrumentos de Jt son concordantes con la Constitución. Esto ocasionará que el juez constitucional en próximas ocasiones no cuente con fundamentos claros sobre la exequibilidad del Acto Legislativo y, en consecuencia, se abran debates sobre su constitucionalidad que cambien lo dispuesto por la Corte Constitucional.

\section{ANÁLISIS DE LOS CARGOS FORMULADOS EN CONTRA DE LAS DISPOSICIONES DEL MJP}

La demanda de inconstitucionalidad contra el msp que suscitó el debate sobre la constitucionalidad de los mecanismos de st allí estableci-

un caso determinado. Siguiendo a Diego López Medina (2006), esta figura es apropiada por los jueces para examinar el margen de decisión con el que cuentan para resolver un caso. En tanto haya una reiteración jurisprudencial consolidada de una ratio frente a una situación jurídica, el juez estará vinculado a resolverla conforme a esa reiteración y solo podrá alejarse de esta con fundamentos muy sólidos; una línea jurisprudencial dispersa, por el contrario, otorga al juez un amplio margen de decisión. dos fue presentada por Gustavo Gallón Giraldo y otros representantes de la Comisión Colombiana de Juristas. ${ }^{5}$ En esta se propone como petición principal que el contenido del Acto Legislativo sustituye un pilar fundamental de la Constitución a saber: "la obligación del Estado colombiano de respetar y garantizar los derechos fundamentales de todas las personas residentes en Colombia" (Gallón et al., 2012, p. 3). Según los demandantes, de este deber general se desprende uno específico pues "el respeto y la garantía de los derechos fundamentales de todas las personas residentes en Colombia exigen que las autoridades estatales investiguen y juzguen todas las violaciones graves de los DDHH incluidas las infracciones graves al DIH" (Gallón et al., 2012, p. 4). Así las cosas, los criterios de priorización y selección del m.p al centrar la investigación penal en los máximos responsables, en los crímenes de guerra cometidos de manera sistemática y permitir la renuncia condicionada de la persecución penal de todos los casos no seleccionados, conlleva una vulneración de la obligación que el Estado colombiano ha adquirido en virtud de los preceptos constitucionales y del bloque de constitucionalidad. ${ }^{6}$

5 Según lo expone en su página web, la Comisión Colombiana de Juristas es una organización no gubernamental domiciliada en Bogotá, con estatus consultivo ante Naciones Unidas, filial de la Comisión Internacional de Juristas y de la Comisión Andina de Juristas. Tiene como mandato el uso de medios jurídicos, de conformidad con los propósitos y principios de la Carta de las Naciones Unidas, para garantizar el pleno respeto en Colombia de los derechos humanos civiles y políticos, económicos, sociales y culturales, así como del derecho humanitario (Comisión Colombiana de Juristas, 2013). Según los demandantes (Gallón et al., 2012, p. 24) esta obligación está consagrada en el preámbulo de la Constitución y sus artículos $1^{\circ}, 2^{\circ}, 12^{\circ}, 29^{\circ}, 93^{\circ}, 228^{\circ}$ y $229^{\circ}$, así como varios instrumentos internacionales que hacen parte del bloque de constitucionalidad como el Pacto Internacional de Derechos Civiles y Políticos (arts. 2.1 y 2.3) y la Convención Americana sobre Derechos Humanos (arts. 1.1. y 25). Asi- 
Aquí hay que anotar que la petición de los demandantes no tiene como fin el que se declare inconstitucional el establecimiento de criterios de priorización y selección dentro de la investigación penal, pues consideran que estas medidas conducen a que las tareas de investigación y juzgamiento se realicen con mayor eficacia. En sus palabras,

lo único que se ha afirmado en la demanda es que no puede el Estado renunciar de antemano a investigar y juzgar graves violaciones de derechos humanos e infracciones al derecho internacional humanitario, pues ello implicaría una negación del acceso a la justicia y de los derechos a la verdad, la justicia y la reparación, así como la abdicación del propósito de lograr un orden justo (Gallón et al., 2012, p. 24).

A continuación se presentan los principales argumentos expuestos en la demanda frente a cada uno de los vocablos señalados como presuntamente inconstitucionales.

- Frente a los vocablos “máximos" y “todos los":7 los demandantes consideran que al no haber una definición jurídica en el cuerpo normativo del Acto Legislativo sobre la categoría “máximos responsables" no existe certeza sobre el alcance que le dará el legislativo y, por tanto, "el Congreso necesariamente excluirá a algu-

mismo, en el escrito de la demanda se hace alusión a la Declaración sobre la Protección de todas las Personas contra las Desapariciones Forzadas (art. 14), a la Convención contra la Tortura y otros Tratos Crueles, Inhumanos o Degradantes (art. 2, 4, 6 y 12) y al Estatuto de la Corte Penal Internacional (preámbulo y arts. 17 y 53).

$7 \quad$ Como lo indican los demandantes, estas dos expresiones deben ser estudiadas en su conjunto puesto que están íntimamente ligadas a los criterios de priorización y selección de casos. nos de los responsables de violaciones graves a los derechos humanos e infracciones graves al DIH de los deberes de investigación y juzgamiento, al impedirles a las autoridades que adelanten investigaciones penales en su contra" (Gallón et al., 2012, p. 27).

Asimismo, argumentan que al restringirse el ejercicio de la acción penal a los "máximos responsables" se está incurriendo en una violación de los derechos de las víctimas del conflicto, principalmente por tres razones:

i. Las víctimas no podrán acudir a la justicia para exigir el juzgamiento de aquellos que no estén en la categoría de "máximos responsables" y no sean seleccionados para el ejercicio de la acción penal.

ii. Las víctimas no tendrán acceso integral a la verdad judicial de los hechos delictivos pues solo se tendrá conocimiento de los hechos cometidos por los "máximos responsables" y habría más laxitud en la investigación de los demás miembros del GAOML.

iii. No existirán garantías de no repetición de lo sucedido en el marco del conflicto para las víctimas, pues la investigación y juzgamiento de todos los responsables son en sí mismas garantías de no repetición, en tanto el conocimiento de los hechos asociados al conflicto evita la repetición de esas conductas. 
- Frente a la frase "cometidas de manera sistemática": Ios demandantes consideran que esta expresión reduce significativamente el ámbito de juzgamiento de los crímenes de guerra a aquellos que sean cometidos de manera sistemática, desconociendo que estos crímenes constituyen graves violaciones a los DD. HH. e infracciones al DIH. Asimismo, resaltan que los crímenes de guerra en virtud de lo dispuesto en el artículo $8^{\circ}$ del Estatuto de Roma se caracterizan por su gravedad y no por su sistematicidad, por lo tanto no es preciso considerar que los crímenes de guerra que se deben enjuiciar son aquellos que son cometidos de manera sistemática. Así, conductas graves pueden quedar en la total impunidad (Gallón et al., 2012, p. 29).

Esta expresión, a juicio de los demandantes, vulneraría los derechos de las víctimas de crímenes de guerra que no hayan sido cometidos de manera sistemática, por cuanto no podrán acceder ante un juez penal para conocer los hechos alrededor de su caso, ni tampoco la decisión penal constituirá una medida de reparación ni una garantía de no repetición (Gallón et al., 2012, p. 30).

Finalmente, para concluir este acápite enunciativo de la demanda que dio origen a la sentencia C-579 de 2013, es importante resaltar los puntos que exaltó Gustavo Gallón en su intervención en la audiencia pública para considerar la inexequibilidad del Acto Legislativo. En primer lugar, el llamado de atención que hizo respecto a la idea según la cual la renuncia condicionada de la investigación penal desconoce las obliga- ciones contraídas por el Estado colombiano de investigar y enjuiciar todas las graves violaciones a los DD. HH. y al DIH (CConst., C-579/2013, J. Pretelt, F. 2.3). En segundo lugar, el Acto Legislativo en su opinión no concreta una armonización plausible entre la justicia y la paz, mucho más teniendo en cuenta que su aplicación se da en el contexto de la sт que es la encargada de enjuiciar las más graves violaciones a los DD. HH. y al DIH, y donde el deber de justicia es más apremiante (CConst., C-579/2013, J. Pretelt, F. 2.5). En tercer y último lugar, porque concluye que la justicia que impone el msp es “distorsionada" pues en vez de buscar una ponderación entre la paz y la justicia lo que hace es reducir el deber de administrar justicia por parte del Estado. Si bien es imposible enjuiciar a todos los responsables cuando se han cometido crímenes de gran envergadura, no se debe privar a las víctimas de su derecho a la justicia (CConst., C-579/2013, J. Pretelt, F. 2.7).

\section{RATIO DECIDENDI}

En el estudio de las peticiones elevadas por los demandantes, la sentencia sub examine trazó, la siguiente regla de derecho:

En aras de facilitar la terminación del conflicto armado interno y el logro de una paz estable y duradera, se podrán determinar criterios de priorización y selección en la investigación penal centrándose en los máximos responsables, siempre y cuando se garantice que todas las conductas que constituyan crímenes internacionales se enjuiciarán, la totalidad de los hechos constitutivos de graves violaciones a los 
DDHH e infracción al DIH le serán imputados a los máximos responsables y se garantizarán los derechos de las víctimas a la verdad, la justicia y la reparación con garantías de no repetición.

Como es evidente en el planteamiento de la regla de derecho que aquí se esboza, los condicionamientos al establecimiento de criterios de priorización y selección en la persecución penal corresponden a las obligaciones que el Estado colombiano ha adquirido en materia de DD. HH. y DIH que el mismo Acto Legislativo ya había incluido en su articulado. ${ }^{8}$

En el siguiente acápite se hará más clara esta afirmación al examinar los argumentos que fundamentan la ratio en el desarrollo del juicio de sustitución.

III. ARGUMENTOS QUE TUVO LA CORTE PARA SOPORTAR DICHA REGLA

Para establecer esta regla de derecho la Corte partió de la integración de la unidad normativa (D. 2067/1991, art. 6) de todo el inciso $4^{\circ}$ del artículo $1^{\circ}$ del Acto Legislativo en mención, puesto que, a su juicio, los vocablos y expresiones demandadas no deben estar descontextualizadas de los parámetros y la teleología que contiene el inciso $4^{\circ}$. Por esto, para el desarro-

8 Confróntese lo establecido en el mismo inciso $4^{\circ}$ del artículo $1^{\circ}$ del Acto Legislativo cuando establece un límite a la configuración normativa del legislador para expedir las leyes estatutarias que determinarán los criterios de priorización en los siguientes términos: "Sin perjuicio del deber general del Estado de investigar y sancionar las graves violaciones a los Derechos Humanos y al Derecho Internacional Humanitario, en el marco de la justicia transicional, el Congreso de la República, por iniciativa del Gobierno Nacional, podrá mediante ley estatutaria determinar criterios de selección".
Ilo del juicio de sustitución, dividió la norma que se pretende que sustituyó el pilar fundamental de la Constitución (inciso $4^{\circ}$ ) referido por los demandantes en cinco reglas diferentes (componentes de la premisa menor), examinando una a una su concordancia con los parámetros constitucionales.

A continuación, en los literales A) al D) se analizarán las determinaciones de la Corte al realizar el mencionado juicio de sustitución.

\section{A. Posibilidad de centrar los esfuerzos en la investigación penal en la persecución de los delitos internacionales como los delitos de lesa humanidad, los crímenes de guerra y el genocidio}

La Corte determinó que los criterios de priorización y selección que permiten centrar los esfuerzos en la investigación penal están acordes con el pilar de la Constitución que los demandantes consideraron sustituido, toda vez que el deber estatal de investigar, juzgar y sancionar las graves violaciones a los DD. HH. y al DIH no es una regla absoluta y permite limitaciones. Así, por ejemplo, señala que el contenido del artículo 6.5 del Protocolo II Adicional a los Convenios de Ginebra permite la concesión de amnistías frente a las personas que hayan hecho parte activa en el conflicto. ${ }^{9}$

Sin embargo, como bien lo resaltan los demandantes, existe un núcleo duro que no admite

\footnotetext{
9 En el mismo sentido ver la regla 58 del Derecho Internacional Humanitario Consuetudinario (Doswald-Beck y Henckaerts, 2007).
} 
limitaciones de ninguna índole, compuesto por la persecución de los delitos de genocidio, lesa humanidad y crímenes de guerra. Este punto de vista fue compartido por la Corte al señalar que:

el Acto Legislativo 01 de 2012 se orienta a cumplir con la restricción reconocida por el bloque de constitucionalidad de la necesidad de que en todo caso se investiguen, juzguen y castiguen los delitos de lesa humanidad, genocidio y crímenes de guerra cometidos de manera sistemática (CConst., C-579/2013, J. Pretelt, F. 8.3.2 (ii)).

Asimismo, se halla razón en el planteamiento de la Corte al dotar de valor la cláusula contenida en el inciso $4^{\circ}$ del artículo $1^{\circ}$ del Acto Legislativo que delimita el margen de configuración normativa con que cuenta el legislativo para expedir las leyes estatutarias que fijarán las reglas de selección y priorización, y que señala: “Sin perjuicio del deber general del Estado de investigar y sancionar las graves violaciones a Ios Derechos Humanos y al Derecho Internacional Humanitario".

Como se pudo evidenciar en el apartado I, los demandantes omitieron hacer referencia a esta cláusula al pedir la declaratoria de inconstitucionalidad. Al incurrir en tal omisión no tomaron en cuenta las previsiones que dicha cláusula consagra, dejando de lado las limitaciones que esta le impone al Estado y que pueden ser reformuladas de la siguiente manera: se pueden determinar criterios de priorización y selección siempre y cuando estén acordes con el deber general del Estado de investigar y sancionar las graves violaciones a los DD. HH. y al DIH, por eso la importancia de la integración de la unidad normativa que realiza la Corte. ${ }^{10}$

Al realizar la integración normativa de todo el inciso $4^{\circ}$ del Acto Legislativo, como se explicó en su momento, la Corte pudo resaltar el valor que tiene esta cláusula dentro del análisis de constitucionalidad, pues es la que fija el núcleo duro sobre el cual no se puede limitar la persecución penal. ${ }^{11}$

\section{B. Sobre la expresión "cometidos de manera sistemática"}

La Corte estimó que el elemento de la sistematicidad tal y como quedó contenido en el mıp solo se predica frente a los crímenes de guerra. Contrario a lo que sostenían algunos intervinientes en el proceso, ${ }^{12}$ teniendo en cuenta el contenido

10 Según Andreas Forer y Claudia López Díaz (2011, p. 238) esta obligación también existía en el marco del proceso penal especial de Justicia y Paz, desde el auto de segunda instancia de la Corte Suprema de Justicia en el caso del paramilitar alias "el Loro". En efecto, en esa decisión la Sala Penal de dicha Corte afirmó: "Colombia tiene la obligación internacional de investigar, juzgar y condenar a penas adecuadas a los responsables de graves violaciones a los derechos humanos. De igual forma, debe investigar y juzgar a quienes cometan graves infracciones del derecho internacional humanitario y adoptar todas las medidas necesarias para combatir la impunidad, entendida por la Corte Interamericana de Derechos Humanos como la falta de investigación, persecución, captura, enjuiciamiento y condena de los responsables de violaciones a los derechos humanos" (CSJ Penal, 28 may. 2008, Rad. 29560, pp. 30-31).

11 En una publicación reciente Rodrigo Uprimny, Luz María Sánchez y Nelson Camilo Sánchez (2014) resaltaron la importancia de entender ¿qué tanto se debería juzgar y castigar dentro de un plano holístico de la JT? Allí sostuvieron que la idea de un núcleo duro es una noción aún inconclusa. En sus palabras: "Nuestra posición es que por ahora el derecho internacional ha dejado este punto relativamente abierto. Sin embargo, consideramos que dadas las particularidades del caso colombiano, un mínimo de pena privativa de la libertad para los máximos responsables de la guerrilla y otros actores armados (Estado y paramilitares) es deseable desde el punto de vista ético-político, pues permite una paz más sólida y duradera y toma más en serio los derechos de las víctimas" (p. 118).

12 El procurador general de la Nación sostuvo que la expresión "cometidos de manera sistemática” no solo se refería a los crímenes de guerra 
de la ponencia para segundo debate en el Senado colombiano, la corporación pudo identificar desde una interpretación meramente teleológica que lo que buscaba regularse con esta expresión era lo concerniente a los crímenes de guerra.

Ahora bien, centrándose en este análisis, la Corte haciendo referencia a reconocidos tratadistas del derecho penal internacional como Werle y Ambos explica que el carácter de sistematicidad como elemento de los crímenes internacionales hace referencia al "contexto de violencia organizada" o de "macrocriminalidad" en los que se cometen. Para el caso de los crímenes de guerra, recalca, este elemento se satisface cuando se comprueba

un nexo con el conflicto armado como parte de un plan o política [de un GAOML], pues es claro que el conflicto armado exige per se una violencia generalizada contra la población civil que a través de una investigación de contexto permita diferenciarlo de crímenes ordinarios como un daño en bien ajeno o un homicidio (CConst., C-579/2013, J. Pretelt, F. 8.2.5, p. 341).

Sobre esta interpretación, la Corte llega a la conclusión que no hay una sustitución del pilar fundamental de la Constitución de investigar y juzgar las graves violaciones a los DD. HH. y al DIH, pues

esta frase implica que no puedan considerarse como crímenes de guerra delitos aislados sino

sino también al genocidio y a los delitos de lesa humanidad. Desde su perspectiva, no habría posibilidad de juzgar el genocidio cuando se busca la ejecución de los líderes del grupo con el propósito de acabar con este, o los delitos de lesa humanidad que fuesen cometidos de manera generalizada pero que carecieran de sistematicidad (CConst., C-579/2013, J. Pretelt, F. 2.1). que deben tener un nexo o patrón y este nexo directo debe ser con el conflicto armado, lo cual está de acuerdo con el Estatuto de Roma que señala que todos los crímenes de guerra deben tener un nexo con el conflicto armado (CConst., C-579/2013, J. Pretelt, F. 8.3.2. (iii)). [Cursivas añadidas].

Teniendo como referencia esta línea argumentativa asumida por la Corte Constitucional, paradójicamente Ambos y Zuluaga (2014) elevaron su crítica a esta visión en un artículo en el que resaltan el carácter redundante de la asociación del carácter sistemático de los crímenes de guerra con el nexo entre el hecho delictivo y el conflicto armado. En sus palabras:

un solo hecho puede ser sancionado a nivel internacional como crimen de guerra si la existencia del conflicto armado explica el que este haya sido perpetrado. Si la expresión 'cometidos de manera sistemática' realmente equivaliese al nexo que debe existir entre el crimen y un conflicto armado, no tendría ningún sentido haberla incluido en el texto del art. transitorio 66 [de la Constitución Política]. En otros términos, decir crímenes de guerra y 'cometidos de manera sistemática' resultaría en consecuencia redundante; esta sería entonces una expresión vacía y tautológica (p. 175).

Esta afirmación es una crítica al texto del artículo $1^{\circ}$ del Acto Legislativo (cN, art 66 transitorio) realizado por el legislador como constituyente derivado más que a la interpretación que la Corte Constitucional hace sobre este. En efecto, desde la promulgación del Acto Legislativo la expresión "cometidos de manera sistemática", al 
referirse únicamente a los crímenes de guerra, es redundante. Como lo menciona Ambos en un texto anterior, "no existen dudas en cuanto a que la existencia de un crimen de guerra depende de la presencia de un conflicto armado de determinada gravedad y que los hechos se deben dirigir contra personas $u$ objetos protegidos" (2005, p. 406).

Sin embargo, si bien no es técnico jurídicamente hablando referirse a los crímenes de guerra cometidos de manera sistemática, hace bien la Corte en delimitar la hermenéutica de dicha expresión. Así suene redundante la expresión dentro de la disposición normativa, haber declarado su inexequibilidad bajo este argumento hubiera creado mayor incertidumbre a los operadores jurídicos al momento de decidir sus casos, y al legislativo al momento de expedir las leyes estatutarias del mıp. En otras palabras, el razonamiento realizado por la Corte se debe entender como un mal menor, pues si bien perpetuó la redundancia existente en el inciso $4^{\circ}$, concretó su marco interpretativo al asimilarlo con el elemento objetivo del crimen de guerra, cual es que se haya cometido en el contexto de un conflicto armado.

\section{Respecto a la expresión "máximos responsables"}

A juicio de la Corte, la expresión "máximos responsables" no significa una sustitución del pilar fundamental reseñado, por dos razones. En primer lugar, porque no implica que vaya a haber impunidad sobre los hechos relacionados con el conflicto armado interno. El msp lo que consa- gra es que se concentrará la responsabilidad en los "máximos responsables" a los cuales se les imputarán los delitos internacionales y se les sancionará si procediese. Según lo expresa en el proveído:

En este contexto, la obligación de la Fiscalía General de la Nación es encausar todas las graves violaciones a los derechos humanos y al Derecho Internacional Humanitario, establecer si constituyen delitos de lesa humanidad, genocidio o crímenes de guerra y en ese caso imputarlos al menos a un responsable (CConst., C-579/2013, J. Pretelt, F. 8.3.2. (iv)(i), p. 371). [Cursivas añadidas].

En segundo lugar, para la Corte la expresión "máximos responsables" contenida en el Acto Legislativo tiene la finalidad de esclarecer las estructuras de macrocriminalidad y "dedicar esfuerzos y recursos para atender la criminalidad del presente, disuadir la del futuro y fortalecer el Estado Social de Derecho" (CConst, C-579/2013, J. Pretelt, F. 8.3.2. (iv)(ii), p. 372). Bajo esta perspectiva, la finalidad de centrar los esfuerzos en la persecución penal de los "máximos responsables" también garantiza la no repetición de los hechos delictivos, pues permite que los GAOML se desvertebren y devela los patrones de violaciones a los derechos humanos que permitirá que dichas conductas no sean desplegadas en el futuro.

Sobre este punto, coincido en que la limitación de la imputación de los delitos constitutivos de graves violaciones a los DD. HH. y al DIH a los máximos responsables no sustituye el pilar fundamental que exige su investigación y juzga- 
miento. Como bien lo expresó en su momento la Corte, la imputación de los delitos internacionales a los máximos responsables busca centrar los esfuerzos que hace el Ente Acusador al solo imputarlo a las personas con mayor responsabilidad en la comisión de los hechos. ${ }^{13}$ Esta situación, a diferencia de lo que sostenían los demandantes, no es sinónimo de impunidad de facto pues la totalidad de los hechos delictivos les deberán ser imputados a las personas que ostenten esta calidad.

Ahora bien, no ha habido consenso acerca de los razonamientos que tuvo la Corte en este punto. $Y$ no los ha habido porque esta corporación no determinó una definición clara sobre quiénes deben ser entendidos como máximos responsables y, por tanto, es una categoría jurídica abierta que puede estar sujeta a diversas interpretaciones. En este sentido se encamina la preocupación que elevó la Procuraduría General de la Nación dentro del proceso. En su concepto, el Acto Legislativo no determinó ni especificó el alcance de la expresión "máximos responsables",

dejando abierta la posibilidad de que sean excluidos del deber de investigar sus conductas a los determinadores o cómplices en su calidad de partícipes, o que sean excluidos,

13 La categoría de máximo responsable ha sido construida a través del tiempo en el marco de las labores de investigación y juzgamiento llevados a cabo dentro de los tribunales penales internacionales ad hoc. En particular, la Corte Especial para Sierra Leona y las salas extraordinarias de las Cortes de Camboya. Con el uso de la categoría de los máximos responsables estas instancias han buscado que en contextos de graves violaciones a los DD. $\mathrm{HH}$. e infracciones al DIH, los juicios penales se centren en las estructuras criminales organizadas que realizaron dichas conductas, concretamente en las personas y delitos sobre los cuales debe haber mayor reproche (Uprimny, Sánchez y Sánchez, 2014, pp. 124-125). incluso, los autores mediatos o coautores. De esa forma, establecer que los máximos responsables son únicamente quienes tienen responsabilidad principal, implica excluir de investigación a muchos otros victimarios y no conocer la verdad integral de los hechos materia de investigación" (CConst., C-579/2013, J. Pretelt, F. 2.1. pág. 69).

Frente a esta preocupación, la Corte aseveró:

En consecuencia, un máximo responsable puede ser tanto el jefe de un grupo, como también quien haya tenido un rol esencial en la comisión de los crímenes de acuerdo al papel que la persona pudiese jugar dentro de la organización. De hecho, el parámetro del máximo responsable es un criterio ascendente que permite incluir no solamente a quien haya tenido una intervención decisiva en el delito, sino también a otras personas en virtud de criterios como el de la responsabilidad del superior "Command responsibility" o el dominio de aparato organizado de poder "Organisationsherrschaft".

Por lo anterior, el concepto de máximo responsable no puede identificarse necesariamente con el autor de la conducta punible excluyendo a los partícipes, ni con el autor de un delito agravado, ni con un líder, sino que depende de la estructura misma de los delitos de lesa humanidad, genocidio y crímenes de guerra y está relacionada con el concepto de macrocriminalidad para desmembrar la estructura organizada.

Si bien no existe una definición unánime sobre el máximo responsable, los criterios que lo han definido en el Tribunal Penal para la antigua Ex Yugoslavia, el Tribunal Penal Internacional para 
Ruanda y la Oficina del Fiscal de la Corte Penal Internacional tienen en común que a través de esta figura identifican a aquella persona que tiene un rol esencial en la organización criminal para la comisión de cada delito.

Este concepto está relacionado con la doble imputación que implica todo crimen internacional, en el cual no solamente se investiga el hecho individual (imputación individual) sino también el hecho total (“Gesamttat”) que describe el respectivo contexto colectivo de comisión (imputación colectiva).

\section{(...)}

En conclusión, a partir de los criterios internacionales anteriormente expresados se puede señalar que el máximo responsable es aquella persona que tiene un rol esencial en la organización criminal para la comisión de cada delito, es decir, que haya: dirigido, tenido el control o financiado la comisión de los delitos de lesa humanidad, genocidio y crímenes de guerra cometidos de manera sistemática.

Dentro de este concepto se deben incluir entonces, no solamente líderes que hayan ordenado la comisión del delito, sino también conductas a través de las cuales este se haya financiado como el narcotráfico (CConst., C-579/2013, J. Pretelt, F. 8.2.3. p. 330). [Cursivas añadidas].

De la anterior cita es posible deducir que la Corte concibió a los "máximos responsables" como un gran grupo dividido en dos. Por un lado, aquellos que tienen un rol esencial dentro de la estructura de los GAOML, como los jefes o comandantes. Por otro lado, aquellos que colaboraron en la ejecución de los crímenes. Esta concepción de la categoría "máximos responsables" está alineada con la percepción de que los delitos que se cometieron en el conflicto armado interno fueron realizados en el marco de una estructura organizada, en la que existen tanto autores como colaboradores y que, por tanto, las conductas punibles desplegadas corresponden a políticas de GAOML y es posible esclarecer los patrones de macrocriminalidad subyacentes a su accionar. ${ }^{14}$

Desde este punto de vista, la forma en que la Corte Constitucional concibe la categoría de "máximos responsables" se compadece con las definiciones que ha establecido la Fiscalía General de la Nación en instrumentos internos como la Directiva 0001 de $2012 .{ }^{15}$ Estas preceptivas recogen la categoría "máximos responsables" en atención a la aplicación de los criterios subjetivos de priorización y selección de casos en los cuales se examina el carácter del victimario para implementarlos. ${ }^{16}$ Bajo esta mirada, la de-

14 En la determinación de los máximos responsables en un caso concreto se deben tener dos razonamientos: uno, que el criterio de la posición en la estructura jerárquica y el nivel de involucramiento en la comisión de los crímenes perpetuados por el GAOML es apropiado, pues de ahí se puede deducir el nivel de responsabilidad de la persona; dos, que dicha categoría la ostentan personas que al actuar dentro de un GAOML ostentaban una posición de dominio en esa estructura criminal (Uprimny, Sánchez y Sánchez, 2014, pp. 132-133).

15 En ella se define "máximo responsable" en los siguientes términos: "El concepto de máximo responsable se aplica respecto a dos categorías diferentes, a saber: (i) aquel que dentro de la estructura de mando y control de la organización delictiva sabía o podía prever razonablemente la perpetración de crímenes en desarrollo de la ejecución de los planes operativos; y (ii) de manera excepcional, se trata de aquellas personas que han cometido delitos particularmente notorios, con independencia de la posición que ocupaban en la organización delictiva" (p. 3).

16 En palabras de Forer y López Díaz (2011): "Se debe por lo tanto dejar claramente sentado cuáles son los autores que dentro del aparato criminal vamos a investigar, acusar y condenar. Se recomienda que en primer lugar se seleccionen a los autores que hacen parte de los man- 
finición de un "máximo responsable" se corresponde con un análisis dinámico del contexto macrocriminal en el cual se cometen los punibles que se pretenden investigar y juzgar. Así, la identificación de la figura del "máximo responsable" dependerá del caso en particular que se esté investigando, pues si bien usualmente incumbe solamente a los mandos altos de un GAOML puede que, por tratarse de hechos de connotación, los mandos medios o bajos sean tratados bajo esta figura.

En el mismo sentido, el Decreto 3011 de 2013, que reglamentó la Ley 1592 que modificó la Ley 975 o Ley de Justicia y Paz, resaltó esta misma característica al contemplar en su artículo 16 lo siguiente:

La identificación del patrón de macro-criminalidad permite concentrar los esfuerzos de investigación en los máximos responsables del desarrollo o realización de un plan criminal y contribuye a develar la estructura y modus operandi del grupo armado organizado al margen de la ley, así como las relaciones que hicieron posible su operación [cursivas añadidas].

De esta afirmación se puede concluir que, dependiendo de los resultados que arroje la investigación del plan criminal, se podrán identificar los "máximos responsables" sin que quiera esto decir que siempre serán los comandantes o líderes de la organización criminal.

dos superiores; o de la cúpula de la organización criminal; o que estén vinculados al Estado directa o indirectamente; o que tengan capacidad de generar impunidad. Se debe por lo tanto, crear una tipología de los autores que en primer lugar se deben investigar, definiéndolos concretamente para que el operador judicial priorice esas investigaciones" ( $p$. 240). [Cursivas añadidas].
Para Ambos y Zuluaga (2014), en la sentencia C-579 de 2013 la Corte crea una definición compleja de la figura del "máximo responsable", en la que caben tanto los autores como los líderes del GAOML dependiendo de los delitos que se cometan. En sus palabras:

Esta definición propuesta por la Corte es problemática, "ya que no permite ver cómo a través de esta es posible reducir el universo de casos que se deben investigar penalmente. En primer lugar se debe decir, que al parecer la Corte se contradice al afirmar que el cumplimiento de un rol esencial es lo que define la condición de máximo responsable y posteriormente sostener que el concepto de máximo responsable "permite incluir no solamente a quien haya tenido una intervención decisiva en el delito (p. 175).

Se entiende la preocupación de dichos autores pues desde su punto de vista no hay certeza jurídica sobre quién es "máximo responsable". Sin embargo, como se acabó de ver, esta figura al tener un carácter dinámico debe ser identificada en el momento en que se esclarece el patrón de macrocriminalidad, por lo tanto no se puede identificar a priori. Incluso, si así se quisiese, la figura del "máximo responsable" debe atender a las prácticas delictivas de cada GAOML, pues mal haría una norma o jurisprudencia en definir de antemano quién es o no el "máximo responsable" sin tener en cuenta las características especiales de cada caso.

Sobre este punto, se puede concluir que la Corte determinó que la existencia de la categoría "máximo responsable" dentro del articulado del 
MJP no sustituye el pilar fundamental de la Constitución que alegan los demandantes. También es posible afirmar que la noción que elaboró la sentencia se compadece con las definiciones que se han establecido a nivel gubernamental.

\section{Sobre la renuncia condicionada a la persecución penal}

Respecto a la posibilidad de renuncia condicionada de la persecución penal, la Corte estableció que no se sustituía el pilar fundamental de respeto a los derechos humanos y al derecho internacional humanitario, por tres razones.

En primer lugar, dado que el msp establece unos límites claros donde es imposible renunciar a la persecución penal cuando se trata de delitos de lesa humanidad, genocidio y crímenes de guerra cometidos de manera sistemática, la Corte determinó que cumplía con los parámetros que instituye el bloque de constitucionalidad. En consonancia con lo dicho por la Oficina de la Fiscal de la Corte Penal Internacional en su reporte de 2012 sobre la situación de Colombia (International Criminal Court, 2012, párr. 204), la Corte Constitucional en la sentencia C-579/2013 (J. Pretelt, F. 8.3.2. (v)(i), p. 376) señaló que

el Acto legislativo 01 de 2012 establece precisamente la necesidad de centrar la investigación, el juzgamiento y la sanción en los crímenes de lesa humanidad, en el genocidio y en los crímenes de guerra cometidos de manera sistemática, lo cual cumpliría plenamente con esta restricción, pues desarrolla la obligación de investigar estos delitos (teniendo en cuenta que como ya se dijo el elemento sistemático es intrínseco a los crímenes de guerra).
Así pues, la figura de la renuncia condicionada de la persecución penal no es predicable a los "máximos responsables" de cometer crímenes que la comunidad internacional condena.

En segundo lugar, el Acto Legislativo contempla unos requisitos señalados en el inciso $5 \mathrm{del}$ artículo $1^{\circ}$ para la procedencia de la renuncia condicionada: i) la dejación de las armas; ii) el reconocimiento de la responsabilidad; iii) la contribución al esclarecimiento de la verdad y a la reparación integral a las víctimas; iv) la liberación de los secuestrados; y v) la desvinculación de los menores de edad reclutados ilícitamente.

En tercer lugar, la Corte considera que la renuncia condicionada de la persecución penal está en armonía con la finalidad de prevención que busca el derecho penal, más que la de retribución, y hace énfasis en que en los procesos de JT es necesario dejar a un lado el retribucionismo.

Para finalizar, la Corte hace una interpretación de los momentos en que procede la aplicación de una u otra de las medidas contempladas en el mup, en los siguientes términos:

Como se dijo en el análisis de la premisa menor, cada una de estas consecuencias se aplica a eventos distintos: la suspensión condicional total de la ejecución de la pena se aplica frente a casos no seleccionados; por lo anterior, si la suspensión condicional de la ejecución de la pena no es total puede aplicarse a los casos seleccionados; las sanciones extrajudiciales serían aplicadas como consecuencia de los mecanismos extrajudiciales; las penas alternativas, son penas que reemplazan a la que ordinariamente correspondería cumplir 
y las modalidades especiales de ejecución y cumplimiento de la pena se pueden aplicar si se impone una condena en firme para casos seleccionados o no seleccionados (CConst., C-579/2013, J. Pretelt, F. 8.3.2. (vi). p. 380).

En el literal e) se estudiarán los parámetros que fija la Corte para la promulgación de las leyes estatutarias, y en el acápite IV se hará un breve análisis sobre la forma en que la Corte desarrolló el juicio de sustitución.

\section{E. Criterios del MJP que deben estar contemplados en las leyes estatutarias}

De modo enunciativo, aquí se hará un recuento de los seis parámetros que fijó la Corte en la sentencia C-579/2013 y que deben ser tenidos en cuenta por el Congreso de la República para la promulgación de las leyes estatutarias (J. Pretelt, F. 8.4., p. 388). De antemano, se identificó que muchas de las previsiones resaltadas por la Corte tienen correspondencia con lo dispuesto en instrumentos de JT existentes en el ordenamiento jurídico colombiano.

i) Parámetro 1: la terminación del conflicto armado respecto del grupo desmovilizado en caso de desmovilización colectiva y de la entrega de las armas y la no comisión de nuevos delitos en la desmovilización individual como requisito para la aplicación del Marco Jurídico para la Paz.

Comentario: como bien evidenciaron Ambos y Zuluaga (2014), la Corte entiende la terminación del conflicto armado basado en un criterio formal cuando se trata de una desmoviliza- ción colectiva. La Corte asoció la terminación de un conflicto armado con la consecución de un Acuerdo de Paz con el Gaoml. Según estos autores esta manera de comprender la terminación del conflicto es minimalista, pues lo asocia al mero cese de hostilidades y no comprende las dimensiones del conflicto en su totalidad, en términos de daño a la democracia y al Estado de Derecho (p. 169).

Sin embargo, no debe mirarse la posición asumida por la Corte de manera negativa, toda vez que en la medida que el mıp está compuesto de artículos transitorios, la firma de un acuerdo de paz con IOS GAOML es un requisito objetivo y verificable que permite reconocer cuándo son aplicables los artículos 66 y 67 transitorios. Si se entrase a discernir sobre el momento en que finalizan las causas estructurales del conflicto, como el fortalecimiento de la democracia o al Estado de Derecho sería muy complejo definir el momento en que son aplicables las disposiciones contenidas en el MJP.

Este parámetro ya había sido reconocido en el numeral 1 del artículo $10^{\circ}$ de la Ley 975 que consagra los requisitos de elegibilidad para la desmovilización colectiva.

ii) Parámetro 2: salvaguarda de los derechos de las víctimas.

Comentario: este parámetro, por su extensión, debe ser desagregado en un catálogo de garantías mínimas que la Corte establece para salvaguardar los derechos de las víctimas. 
Así se pueden resaltar las siguientes: i) garantía de transparencia del proceso de selección y priorización; ii) garantía de debida diligencia en las investigaciones por graves violaciones a los DD. HH. y al DIH; iii) garantía que toda víctima cuyo caso no sea seleccionado tenga un recurso efectivo para impugnar esa decisión; iv) Otorgamiento de asesoría especializada a las víctimas; v) garantía del derecho de reparación integral; y vi) derecho a conocer los restos de sus familiares.

Sobre estas garantías surgen dos dudas. Primera, ¿cuáles son las medidas que se deben adoptar para garantizar la transparencia del proceso de selección y priorización? Segunda, ¿por qué debe haber un recurso efectivo para la víctima cuyo caso no sea seleccionado si se supone que los hechos delictivos que constituyan delitos internacionales al menos le serán imputados a un "máximo responsable?

Sobre la primera, la sentencia se limita a decir que el establecimiento de criterios por medio de una ley estatutaria es un buen primer paso con el ánimo de garantizar la transparencia en este proceso. Sin embargo, establece que se deben complementar con medidas que faciliten la publicidad y el control, sin hacer mayor referencia a estas (F. 8.4.2. (i), p. 391).

Sobre la segunda, si bien debe mantenerse una garantía en la cual la víctima pueda contar con un recurso para impugnar la decisión que adopte la Fiscalía al priorizar o seleccionar un caso, no se entiende por qué una víctima podría encontrarse dentro de un caso no seleccionado pues, como bien lo dijo la Corte en esta sentencia, todos los hechos serán imputados pero centrando los esfuerzos de la investigación en los "máximos responsables" a quienes se les imputarán los hechos. Esta práctica ya está siendo implementada por la Fiscalía General de la Nación (Unidad Nacional de Fiscalías para la Justicia y la Paz, 2012).

iii) Parámetro 3: investigación y juzgamiento de todas las graves violaciones a IOS DD. HH. y al DIH.

Comentario: este parámetro se relaciona con la segunda duda que se expuso anteriormente. No obstante, es importante aquí hacer énfasis en que la Corte establece como finalidad de este condicionamiento el de la construcción de macroprocesos donde, basados en los criterios de gravedad y representatividad, se concentren la investigación y el juzgamiento de todas las graves violaciones a los DD. HH. y al DIH imputadas a un "máximo responsable".

iv) Parámetro 4: priorización de una serie de delitos constitutivos de graves violaciones a los DD. HH. e infracciones al DIH.

Comentario: la Corte determinó como delitos que necesariamente deberán ser juzgados por revestir el carácter de graves violaciones a los DD. HH. y al DIH, los siguientes: i) las ejecuciones extrajudiciales; ii) la tortura; iii) la desaparición forzada; iv) la violencia sexual; ${ }^{17}$

17 La doctrina constitucional abarcada dentro del mup es especialmente compleja en lo que respecta a la investigación de la violencia sexual ocurrida durante y con ocasión del conflicto armado, pues estos casos 
v) el desplazamiento forzado; y vi) el reclutamiento ilícito.

Cabe decir acá que estos delitos que la Corte determinó como prioritarios ya se encontraban en su mayoría dentro del llamado "plan de acción de casos a priorizar" de la Unidad para la Justicia y la Paz de la Fiscalía General de la Nación. En efecto, en el objetivo 2.2 de dicho plan se lee:

Adelantar investigaciones respecto de los postulados por delitos de Desaparición Forzada, Desplazamiento Forzado, Secuestro, Reclutamiento llícito, violencia basada en género y aquellos hechos que en las regiones ocasionaron mayor conmoción por la gravedad y barbarie en que fueron cometidos o por la representación social, política e institucional de las víctimas, tratándose de líderes sociales, políticos, periodistas, sindicalistas, defensores de derechos humanos y servidores públicos.

v) Parámetro 5: requisitos de elegibilidad para la procedencia de la aplicación de criterios de selección y priorización.

Comentario: si bien la Corte no los llama requisitos de elegibilidad, los condicionamientos que establece guardan estrecha relación

se caracterizan por el subregistro y, por lo tanto, se comprenden como meros hechos aislados. Sin embargo, como lo ha resaltado la Corporación sISMA mujer (2011, pp. 96-97), al establecer el nexo causal entre el acto de violencia sexual y un ataque ocurrido en el marco del conflicto armado en un contexto determinado, entendido como un plan o política de la organización, permite que incluso tratándose de un solo acto sexual se pueda imputar el crimen a la persona. Esta comprensión del fenómeno se compadece con lo definido por la Corte en la presente sentencia pues si se prueba que los actos de violencia sexual fueron cometidos de manera sistemática, probando la existencia de un conflicto armado en el territorio de ocurrencia, es posible determinar que dicho ilícito constituye un crimen de guerra. con los contemplados en el artículo 10 de la Ley 975. Esto por cuanto la Corte fija como criterios: i) el deber de contribución efectiva y real al esclarecimiento de la verdad y a la reparación a las víctimas; ii) la liberación de todos los secuestrados; y iii) la desvinculación de todos los menores de edad de las filas de GAOML.

vi) Parámetro 6: obligación de revelación de todos los hechos constitutivos de graves violaciones a los DD. HH. y al DIH.

Comentario: este requisito hace especial énfasis en el procesamiento extrajudicial de los casos no seleccionados. Para la Corte es necesario que se cumpla con el derecho a la verdad con que cuentan las víctimas y que pueden aportar los desmovilizados cuyos casos no sean seleccionados y, por tanto, constituye una obligación en su cabeza y un aporte a la memoria histórica y personal.

Como queda establecida en la sentencia, esta obligación se asemeja a los Acuerdos de Contribución a la Verdad Histórica y la Reparación contemplados en la Ley 1424 de 2010 donde los desmovilizados deben suscribir un compromiso con la verdad histórica para poder acceder a una serie de beneficios penales. 


\section{CRÍTICA AL JUICIO DE SUSTITUCIÓN ELABORADO POR LA CORTE}

El procedimiento realizado por la Corte se basó en la especificación de la premisa menor, que fue de donde se obtuvieron las conclusiones que se expusieron. Sin embargo, esa metodología no se compadece con lo establecido por esa corporación en una línea jurisprudencial decantada donde la sentencia C-574 de 2011 es un buen ejemplo. Alli se establecieron reglas claras y rigurosas para hacer el Ilamado "juicio de sustitución": ${ }^{18}$

En primer lugar [se busca] la Premisa mayor (i) en donde se aprecia si la reforma introduce un nuevo elemento esencial a la Constitución; en segundo término la Premisa menor (ii) en donde se analiza si este reemplaza al originalmente adoptado por el constituyente y, finalmente, la Premisa de síntesis (iii) en donde se compara el nuevo principio con el anterior para verificar, no si son distintos, lo cual siempre ocurrirá, sino si son opuestos o integralmente diferentes, al punto que resulten incompatibles (F. 4.44.5.).

Con respecto a la premisa de síntesis "en donde se compara el nuevo principio con el anterior para verificar, no si son distintos, lo cual siempre ocurrirá, sino si son opuestos o integralmente diferentes, al punto que resulten incompatibles" (F. 4.44.5.), ${ }^{19}$ puede observarse en la jurispru-

18 Este juicio también es conocido como "test de efectividad" en algunas sentencias.

19

Reiterado por la Corte Constitucional en la sentencia C-249 de 2012 (M. P. Juan Carlos Henao). dencia constitucional que su análisis se centra en determinar:

(i) si las normas constitucionales a reformar siguen siendo las mismas antes y después de la reforma, porque si las normas después de la revisión resultan ser idénticas, entonces no ha existido reforma constitucional, sino que se ha encubierto con el ropaje de la reforma una decisión política singular, (ii) que el cambio no dio lugar a que se establecieran normas ad hoc o particulares, y (iii) que no se hayan sustituido tácitamente a través de la reforma otros principios estructurales de la Constitución, dando lugar al fraude de la Constitución (F. 4.44.7). [Cursivas añadidas].

En efecto, como lo trajo a colación el Fiscal General de la Nación en su concepto presentado a la Corte Constitucional en el marco de este proceso (CConst., C-579/2013, J. Pretelt, F. 13.3-13.5), la Corte Constitucional debió haber estudiado si la norma perseguía un fin válido y si el establecimiento de mecanismos de st era un medio idóneo y menos lesivo. Asimismo, y más importante aún para determinar la premisa de síntesis, debió estudiar si la limitación al derecho a la justicia con la institución de mecanismos de sт no era una sustitución tácita.

Por la manera en la que abordó la Corte el Ilamado "juicio estricto de sustitución" en la presente sentencia, se evidencia una falta de rigurosidad en los pasos a seguir con miras a ponderar las limitaciones al derecho a la justicia con los mecanismos de Jт. Esta corporación argumentó bajo el presupuesto que las normas contenidas en el inciso $4^{\circ}$ del artículo $1^{\circ}$ del Acto Legislativo no 
constituían una sustitución a un elemento definitorio de la Constitución, en vez de realizar un análisis donde esta fuera la conclusión evidente. Entonces, lo que se resalta es que el análisis de la Corte fue autojustificativo, tal como se dijo al inicio de este documento, ya que solo mostró las razones por las cuales las disposiciones del mup están acordes con la Constitución y no siguió las reglas que permiten una verdadera ponderación de los principios constitucionales en colisión. ${ }^{20}$

Desde este punto de vista, hay un verdadero estudio material en todo el sentido de la palabra que se aleja de los estándares establecidos por la jurisprudencia constitucional para elaborar el juicio de sustitución, ${ }^{21}$ amparado en el precepto constitucional según el cual los actos legislati-

20 Para Gustavo Emilio Cote y Diego Fernando Tarapués (2014), "al extraer obligaciones concatenadas del pilar fundamental para luego introducirlas como piezas relevantes de la ponderación y para el resultado del análisis estricto de sustitución, la Corte revive la crítica al hecho de que ella termine estableciendo cuáles son los elementos definitorios de la constitución que son insustituibles. La indeterminación normativa de los pilares y la amplia creatividad de la Corte pueden ser problemáticos cuando queda abierta la posibilidad de asociarle a la premisa mayor cualquier tipo de obligación, sin que resulte directamente de las expresiones contenidas en el pilar fundamental. Lo anterior implica que los límites del juicio de sustitución pasan a ser definidos por la misma Corte y no propiamente por la Constitución" ( $p$. 227).

21 Sobre este punto vale la pena reseñar lo dicho por Diana Margarita Fuentes Becerra (s.f): "en la sentencia C-572 de 2004, delineó algunos de los requisitos esenciales que debe reunir una demanda contra un acto reformatorio de la Constitución, cuando los cargos en que se fundamenta son vicios de competencia. Así, en esta providencia, la Corte determinó que la demanda no puede basarse exclusivamente en la afirmación de la vulneración de ciertos derechos consagrados en la Carta sin determinar el por qué esa vulneración efectivamente se da y de qué manera desborda el poder de reforma. Es decir, la Corte no puede proceder al estudio de demandas de actos reformatorios de la Carta Política que atacan únicamente el acto por la violación de derechos previstos en la Constitución, ya que tal estudio desvirtuaría el control de constitucionalidad de este tipo de actos, el cual se limita a vicios de forma, los cuales pueden ser de competencia o de trámite" (párr. 13). vos están sujetos a un control formal por parte de la Corte Constitucional (cN, art. 241, num. $1^{\circ}$ ).

Así las cosas, es posible concluir que la sentencia que estudió el inciso $4^{\circ}$ del artículo $1^{\circ}$ del msp no constituye per se un precedente jurisprudencial cuyo rigor permita a la Corte en próximas decisiones, cuando verdaderamente se aplique el juicio de sustitución, llegar a las mismas conclusiones a las que se llegó en esta decisión. Con esto en mente, no es extraño que la Corte Constitucional en próximas demandas reabra el debate frente a lo decidido acá y no se atenga a lo dispuesto en la sentencia C-579 de 2013. En tiempos posteriores y con la aplicación del msp en la práctica jurídica se verán sus consecuencias, pero lo seguro es que si se da aplicación a los parámetros del juicio de sustitución muy factiblemente las conclusiones contempladas en la sentencia en análisis pueden verse modificadas.

\section{Referencias}

Ambos, K. y Malarino, E. (2005). La parte general del Derecho Penal Internacional. Montevideo: Fundación Konrad-Adenauer.

Ambos, K. y Zuluaga, J. (2014). Justicia de transición y Constitución. Análisis de la sentencia C-579 de 2013 sobre Marco Jurídico para la Paz. Zeitschrift für Internationale Strafrechtsdogmatik, (4), 165-176.

Comisión Colombiana de Juristas. (2013). ¿Quiénes somos? Obtenido de coljuristas: 
http://www.coljuristas.org/quienes_somos. php?idioma $=$ es\&grupo $=2$

Corporación sISMA mujer. (Abril, 2011). Crímenes de lesa humanidad, violencia sexual y justicia de género en Colombia. Obtenido de sismamujer: http://www.sismamujer.org/ wp-content/uploads/2014/08/05.2011. Cr\%C3\%ADmenes-de-Lesa-Humanidad-Violencia-Sexual-y-Justicia-de-G\%C3\%A9neroen-Colombia.pdf

Corte Constitucional. Sentencia C-249 de 2012. (M. P.: Juan Carlos Henao: marzo 29 de 2012).

Corte Constitucional. Sentencia C-099 de 2013. (M. P.: María Victoria Calle Correa: febrero 27 de 2013).

Corte Constitucional. Sentencia C-370 de 2006. (M. P.: Manuel José Cepeda Espinosa; Jaime Córdoba Triviño; Rodrigo Escobar Gil; Marco Gerardo Monroy Cabra; Álvaro Tafur Galvis; Clara Inés Vargas Hernández: mayo 18 de 2006).

Corte Constitucional. Sentencia C-574 de 2011. (M. P.: Juan Carlos Henao: julio 22 de 2011).

Corte Constitucional. Sentencia C-579 de 2013

(M. P.: Jorge Ignacio Pretelt Chaljub: agosto 28 de 2013).

Corte Constitucional. Sentencia C-715 de 2012. (M. P.: Luis Ernesto Vargas Silva: septiembre 13 de 2012).
Corte Constitucional. Sentencia C-771 de 2011. (M. P.: Nilson Pinilla Pinilla: octubre 13 de 2011).

Corte Suprema de Justicia. Sala Penal, 28 may. 2008, A. Ibañez. Rad. 29560.

Cote Barco, G. E. y Tarapués Sandino, D. F. (2014). El Marco Jurídico para la Paz y el análisis estricto de sustitución de la Constitución realizado en la sentencia C-579 de 2013. En K. Ambos (Coord.), Justicia de transición y Constitución: análisis de la sentencia C-579 de 2013 de la Corte Constitucional. Bogotá: Editorial Temis.

Doswald-Beck, L. y Henckaerts, J. M. (2007). El derecho internacional humanitario consuetudinario. Buenos Aires: Comité Internacional de la Cruz Roja.

Fiscalía General de la Nación. (2012). Directiva 0001 de 2012. "Por medio de la cual se adoptan unos criterios de priorización de situaciones y casos, y se crea un nuevo sistema de investigación penal y de gestión de aquellos en la Fiscalía General de la Nación".

Forer, A. y López Díaz, C. (2011). Selección y priorización de casos como estrategia de persecución penal en la justicia transicional en Colombia. En K. Ambos (coord.), Selección y priorización como estrategia de persecución en los casos de crímenes internacionales: un estudio comparado. Bogotá: Deutsche Gesellschaft für Internationale Zusammenarbeit (giz). 
Fuentes, D. (s. f.). Control de constitucionalidad de los actos legislativos. Obtenido de Avance Jurídico: http://www.avancejuridico.com/actualidad/articulos/aj_actos1.html

Gallón Giraldo, G., Esparza Calderón, F., Díaz Márquez, M., Rivera Rugeles, J. C. (2012). Demanda de inconstitucionalidad contra el acto legislativo 01 de 2012 (parcial).

Gallón Giraldo, G. (25 de julio de 2013). Intervención en la audiencia pública sobre la constitucionalidad del Marco Jurídico para la Paz.

International Criminal Court. (Noviembre, 2012). Office of the Prosecutor. Situation in Colombia: Interim Report.
López Medina, D. (2006). El derecho de los jueces. Bogotá: Universidad de los Andes/Legis.

Unidad Nacional de Fiscalías para la Justicia y la Paz. (Enero 10 de 2012). Plan de acción de casos a priorizar por la Unidad Nacional de Fiscalías para la Justicia y la Paz. Recuperado de fiscalía: http://www.fiscalia.gov.co/ jyp/wp-content/uploads/2012/04/Plan-deAccion-de-Priorizacion-de-la-Unidad.pdf

Uprimny Yepes, R., Sánchez, L. M. y Sánchez, N. C. (2014). Justicia para la paz: crímenes atroces, derecho a la justicia y paz negociada. Bogotá: Centro de Estudios de Derecho, Justicia y Sociedad (Dejusticia). 